\title{
Expression of $\beta$-amyloid precursor protein in refractory epilepsy
}

\author{
XIUTIAN SIMA $^{1}$, JIANGUO XU ${ }^{1}$, JINMEI $\mathrm{LI}^{2}$, WEIYING ZHONG ${ }^{1}$ and CHAO YOU ${ }^{1}$ \\ ${ }^{1}$ Department of Neurosurgery, West China Hospital of Sichuan University; ${ }^{2}$ Department of Neurology, \\ West China Hospital of Sichuan University, Chengdu, Sichuan 610041, P.R. China
}

Received June 13, 2013; Accepted February 5, 2014

DOI: $10.3892 / \mathrm{mmr} .2014 .1977$

\begin{abstract}
A P P)$, also known as $\mathrm{A} \beta$ peptide, has a key role in the pathogenesis of Alzheimer's disease, and is also likely to be involved in the development of refractory epilepsy. The mechanism behind the association between $\beta-A P P$ and refractory epilepsy remains to be elucidated. The aim of the present study was to examine the levels of $A P P$ mRNA and $\beta-A P P$ protein in patients with refractory epilepsy. Tissue samples were obtained from patients with chronic pharmacoresistant epilepsy who underwent surgery. Levels of $A P P$ mRNA and $\beta-A P P$ protein in epileptic temporal lobe and hippocampal tissue were assessed using quantitative polymerase chain reaction, immunohistochemistry and immunofluorescence. The expression levels of protein significantly increased in the temporal cortex and the hippocampus of the patients with epilepsy. $\beta$ - $A P P$ may thus contribute to the pathogenesis of refractory epilepsy.
\end{abstract}

\section{Introduction}

Epileptic seizures may occur in the progression of neurodegenerative disorders, including Alzheimer's disease (AD), indicating a shared pathogenesis (1). Animal models of AD-like amyloid pathogenesis demonstrate an increased sensitivity to pentylenetetrazole-induced seizures, with more severe seizure types (2). These studies indicate that epileptic seizures may be associated with the pathological processes of neurodegenerative disorders.

Overexpression of $\beta$-amyloid precursor protein $(\beta-A P P)$ is a histopathological characteristic of degenerative diseases, including AD and Down's syndrome. Certain studies have also indicated that $\beta$-APP has a role in refractory epilepsy. For example, Shoham and Ebstein (3) reported that a mouse model of AD-like amyloid pathogenesis was more prone to epileptic seizures. Sheng et al (4) reported that $\beta$-APP and interleukin-1 $\alpha$ had a potential role in neuronal dysfunctions,

Correspondence to: Professor Chao You, Department of Neurosurgery, West China Hospital of Sichuan University, 37 Guoxuexiang, Chengdu, Sichuan 610041, P.R. China

E-mail: youchao1977@163.com

Key words: $\beta$-amyloid precursor protein, refractory epilepsy including hyperexcitability, and Willoughby et al (5) reported that a 168 -nucleotide exon from spliced $A P P$ mRNA increased kainic acid-induced seizures in the rat hippocampus. However, the role of $\beta-A P P$ in human refractory epilepsy remains to be elucidated. Axonal sprouting and neural network reorganization are frequent characteristics in refractory epilepsy, while $A P P$ may have a role in growing neuronal axons (6). It was hypothesized that $\beta-A P P$ is also involved in the pathological mechanisms of axon damage, axon growth and network reorganization observed in refractory epilepsy. Hence, the present study examined the $\beta$-APP mRNA and protein levels in temporal lobe and hippocampal tissue of 36 patients with refractory epilepsy using quantitative polymerase chain reaction (qPCR) and immunoactivity.

\section{Materials and methods}

Subjects. Tissue samples from the 36 patients with refractory epilepsy who were included in the present study were obtained from the Department of Neurosurgery of the West China Hospital of Sichuan University (Chengdu, Sichuan, China). Patients underwent resection of the temporal lobe or hippocampal tissues or both. Prior to surgery, informed consent was obtained for the use of human brain tissue for research, and the study was approved by the Ethics Committee of West China Hospital of Sichuan University. At least three neuropathologists reviewed all the cases. The diagnosis of the seizure type was confirmed according to the 2001 International Classification of Epileptic Seizures of the International League Against Epilepsy (7).

Prior to surgery, lesions were localized in all the patients by brain magnetic resonance imaging and 24-h electroencephalography (EEG) or video-EEG. Intraoperative electrocorticography was performed to further localize the epileptic lesion prior to resection in all patients.

All the patients were refractory to maximal doses of at least two or more antiepileptic drugs, including phenytoin, valproic acid, carbamazepine, phenobarbital, topiramate and lamotrigine. Table I summarizes the clinical features of these patients.

The control group biopsy samples were obtained from cases of brain trauma or herniation due to cerebral hemorrhage. Two neuropathologists reviewed these cases. The clinical features of the control group are listed in Table II. Written informed consent was obtained from all subjects participating in the present study, and the research protocol was approved by the ethics committee of Sichuan University. 
Tissue preparation. For each sample, one portion of resected brain tissue was immediately placed in a CryoVial ${ }^{\circledR}$, soaked in buffered diethyl procarbonate $(1: 1,000)$ for $24 \mathrm{~h}$ and stored in liquid nitrogen in preparation for mRNA analysis. The remainder of each sample was fixed in $10 \%$ buffered formalin. Subsequent to being fixed in formalin for 24 to $48 \mathrm{~h}$, paraffin-embedded tissue was sectioned at 4-8 $\mu \mathrm{m}$ and mounted on polylysine-coated slides for immunohistochemical analysis. The sections were processed for hematoxylin-eosin, Nissl and silver nitrate staining.

RNA extraction. Total RNA was isolated from individual brain tissue samples selected randomly, using TRIzol ${ }^{\circledR}$ (Invitrogen, Life Technologies, Carlsbad, CA, USA) according to the manufacturer's instructions [two cases (E12 and 27) from epileptic temporal tissue, two cases (C1 and C3) from control temporal tissue, two cases from epileptic hippocampi (E1 and E9) and one case from control hippocampi (C11)].

The quality and purity of the total RNA was examined through electrophoresis on a $1 \%$ agarose gel, followed by staining with ethidium bromide to determine the relative intensities of the 28, 18 and 5.8S rRNA bands. Absorbance at $260 \mathrm{~nm}\left(\mathrm{~A}_{260}\right)$ and $280 \mathrm{~nm}\left(\mathrm{~A}_{280}\right)$ were measured spectrophotometrically, and the $A_{260} / A_{280}$ ratios were calculated. RNA was prepared for further study when the agarose gel electrophoresis was of adequate quality and the $\mathrm{A}_{260} / \mathrm{A}_{280}$ ratios were between 1.8 and 2.1. All the RNA samples were stored at $-80^{\circ} \mathrm{C}$.

$q P C R$. According to the manufacturer's instructions, qPCR was performed using $1 \mu 1$ Moloney's murine leukemia virus reverse transcriptase (Promega Corporation, Madison, WI, USA), RNAase inhibitor, $2.5 \mathrm{mM}$ dNTP mixer, 5X RT buffer [250 mM Tris-HCl, (pH 8.3), $200 \mathrm{mM} \mathrm{KCl,} 40 \mathrm{mM} \mathrm{MgCl}$ and $5 \mathrm{mM}$ dithiothreitol) and $3 \mu \mathrm{g}$ RNA with the PCR mixture having a total volume of $10 \mu 1$. The PCR mixture was diluted 10 times as the template. The reaction for APP and for GADPH as the housekeeping gene was performed on a Rotor-Gene 3000 Realtime PCR system (Qiagen, Hilden, Germany). The primer was synthesized as follows: Forward, 5'-CGACCGAGGACTGACCACT-3' and reverse, 5'-CTATGAC AACACCGCCCAC-3'. The PCR reaction was performed in a thermal cycler for 40 cycles of $10 \mathrm{sec}$ at $95^{\circ} \mathrm{C}, 15 \mathrm{sec}$ at $57^{\circ} \mathrm{C}, 20 \mathrm{sec}$ at $72^{\circ} \mathrm{C}$ and $5 \mathrm{sec}$ at $85.5^{\circ} \mathrm{C}$. The fluorescence intensity was examined at $85.5^{\circ} \mathrm{C}$. The linear range of amplification and the melting curve were delineated. The fluorescence result was analyzed using Rotor-gene 6.0 (Qiagen). The target amount was divided by $\beta$-actin to obtain a normalized target value.

Histopathological staining. Hematoxylin-eosin, Nissl and silver nitrate staining were performed according to the manufacturer's instructions (Beyotime Institute of Biotechnology, Beijing, China). The Olympus PM20 automatic microscope (Olympus, Tokyo, Japan) was used for image acquisition. The balloon cell change and the loss of neuronal cell population in the temporal lobe were accompanied by reactive glial proliferation. The reduction and degeneration of neuronal cell populations were also evident in the granular cell layer of the hippocampus. Furthermore, there was a definite disarray in the arborization of axonal fibers. In the paraffin sections,
Table I. Clinical features of patients with refractory epilepsy.

\begin{tabular}{lc}
\hline Total & Value \\
\hline Male/female, $\mathrm{n}$ & $20 / 16$ \\
Mean age \pm SD at surgery, & \\
years (range) & \\
Seizure type, $\mathrm{n}$ & 7 \\
CPS & 2 \\
CPS (SPS) & 2 \\
SGS & 21 \\
GTCS & 2 \\
MT & 4
\end{tabular}

Mean seizure duration $\pm \mathrm{SD}$, years (range)

$18.73 \pm 13.45(3-46)$

AEDs, $n$

2

$>2$

Resection tissue, $\mathrm{n}$

TNl

$\mathrm{TN} \mathrm{Hl}$

3

$\mathrm{TNr}$

12

$\mathrm{TN} \mathrm{Hr}$

Pathological results, $\mathrm{n}$

nl

10

$\mathrm{g}$

$\mathrm{nl}$ and $\mathrm{g}$

4

$\mathrm{g}, \mathrm{nl}$ and nd

12

ac

$\mathrm{g}$ and a

3

nad

3

2

CPS, complex partial seizure; SPS, simple partial seizure; SGS, secondarily generalized seizure; GTCS, generalized tonic-clonic seizure; MT, multiple types (including tonic-clonic, tonic, clonic and complex partial seizures); TN, temporal neocortex; $\mathrm{H}$, hippocampus; 1, left; r, right; nl, neuron loss; g, gliosis; nd, neuronal degeneration; ac, astrocytosis; a, atrophy; nad, no abnormal finding; AEDs, antiepileptic drugs; SD, standard deviation.

the anatomical integrity of the hippocampus was not able to be defined with any degree of certainty at the microscopic level. Focal gliosis, loss of neuronal cells, chromatolysis and pyknotic changes in neurons were detected.

Immunohistochemistry. All paraffin-embedded samples were sectioned at $4 \mu \mathrm{m}$ for immunohistochemistry and 6-8 $\mu \mathrm{m}$ for immunofluorescence, and were then placed on polylysine-coated slides. Immunohistochemistry was performed according to the manufacturer's instructions (Zhongshan Golden Bridge Biotechnology, Co., Inc., Beijing, China). Paraffin sections were deparaffinized in xylene and graded ethanol $(100,95,80$ and $70 \%)$, followed by incubation with $\mathrm{H}_{2} \mathrm{O}_{2}(0.3 \% ; 15 \mathrm{~min})$. The sections were heated in a microwave oven for $10 \mathrm{~min}$ at $98^{\circ} \mathrm{C}$ in citrate buffer ( $\mathrm{pH} \mathrm{6)}$ ) for antigen retrieval and then blocked in normal goat serum (1:10) for 
Table II. Clinical features of the control cases.

\begin{tabular}{lc}
\hline Total & Value \\
\hline Male/female, $\mathrm{n}$ & $7 / 8$ \\
Mean age $\pm \mathrm{SD}$, years (range) & $38.13 \pm 10.86(19-53)$ \\
Resection tissue, $\mathrm{n}$ & 7 \\
$\mathrm{TNl}$ & 3 \\
$\mathrm{TNr}$ & 2 \\
$\mathrm{TNl}$ and $\mathrm{Hl}$ & 3 \\
$\mathrm{TNr}$ and $\mathrm{Hr}$ & \\
Etiology, $\mathrm{n}$ & 10 \\
Trauma & 5 \\
CH and BH & \\
Tissue pathology, $\mathrm{n}$ & 15 \\
nad &
\end{tabular}

TN, temporal neocortex; $\mathrm{H}$, hippocampus; 1, left; r, right; $\mathrm{CH}$, cerebral hemorrhage; $\mathrm{BH}$, brain hernia; nad, no abnormal finding; SD, standard deviation.

10 min (Zhongshan Golden Bridge, Inc., Beijing, China). The sections were incubated with primary polyclonal antibodies of anti-human $\beta$-APP (1:75; Santa Cruz Biotechnology Inc., Santa Cruz, CA, USA) for $16 \mathrm{~h}$ at $4^{\circ} \mathrm{C}$, then with biotin-linked anti-rabbit secondary antibodies for $10 \mathrm{~min}$ at $36^{\circ} \mathrm{C}$. The immunoreactivity was observed using 3,3'-diaminobenzidine (DAB+; Zhongshan, Beijing, China). The blank controls were obtained by substituting the primary antibody with PBS, and the hippocampus of a 68-year-old patient with AD was used as the positive control. The immunoreactivity was visualized using an Olympus PM20 automatic microscope (Olympus) and analyzed with a TC-FY-2050 pathology system (Yuancheng, Inc., Wuhan, Hubei, China).

Immunofluorescence. Paraffin sections were deparaffinized in xylene and graded ethanol as aforementioned, then heated using a microwave oven for $10 \mathrm{~min}$ at $98^{\circ} \mathrm{C}$ in citrate buffer $(\mathrm{pH} 6)$ for antigen retrieval. The sections were blocked in calf serum with $0.3 \%$ triton for $1 \mathrm{~h}$ and then in normal goat serum for $5 \mathrm{~h}$ (Zhongshan Golden Bridge, Inc., Beijing, China). The sections were incubated with primary antibody, polyclonal rabbit anti-human $\beta$ - $A P P$ (1:100; Santa Cruz Biotechnology, Inc.), for $16 \mathrm{~h}$ at $14-18^{\circ} \mathrm{C}$, followed by fluorescein isothiocyanate-conjugated affinipure goat anti-rabbit immunoglobulin $\mathrm{G}$ (diluted at 1:200, Zhongshan Golden Bridge, Inc.) for $5 \mathrm{~h}$ at $14-18^{\circ} \mathrm{C}$. The fluorescence-stained sections were observed using laser scanning confocal microscopy (Leica Microsystems Heidelberg GmbH, Mannheim, Germany).

Statistical analysis. SAS 10.0 (SAS Institute Inc., Cary, NC, USA) was used for the semiquantitative statistical analysis of the immunohistochemistry and immunofluorescence results. For immunohistochemistry, labeled tissue sections were examined independently by two observers to determine the presence or absence of specific immunoreactivity. The number of positive cells was counted from four representative fields
Table III. $\mathrm{A}_{260}$ and $\mathrm{A}_{280}$ and the $\mathrm{A}_{260} / \mathrm{A}_{280}$ ratios of the samples.

\begin{tabular}{llll}
\hline Samples & $\mathrm{A}_{260}$ & $\mathrm{~A}_{280}$ & $\mathrm{~A}_{260} / \mathrm{A}_{280}$ \\
\hline E12 & 0.219 & 0.105 & 2.09 \\
E27 & 0.125 & 0.061 & 2.06 \\
E1 & 0.251 & 0.124 & 2.03 \\
E9 & 0.099 & 0.050 & 1.98 \\
C1 & 0.146 & 0.071 & 2.04 \\
C3 & 0.146 & 0.072 & 2.03 \\
C11 & 0.166 & 0.081 & 2.05 \\
\hline
\end{tabular}

A, absorbance.

Table IV. APP, $\beta$-actin and normalized target values.

\begin{tabular}{llll}
\hline Samples & APP & $\beta$-actin & $A P P / \beta$-actin \\
\hline E12 & $3.50 \times 10^{-3}$ & $1.03 \times 10^{-2}$ & $3.40 \times 10^{-1}$ \\
E27 & $5.30 \times 10^{-3}$ & $1.03 \times 10^{-2}$ & $5.15 \times 10^{-1}$ \\
E1 & $6.49 \times 10^{-3}$ & $1.22 \times 10^{-2}$ & $5.32 \times 10^{-1}$ \\
E9 & $1.64 \times 10^{-3}$ & $1.40 \times 10^{-2}$ & $1.17 \times 10^{-1}$ \\
C1 & $2.54 \times 10^{-3}$ & $5.78 \times 10^{-3}$ & $4.39 \times 10^{-1}$ \\
C3 & $2.67 \times 10^{-3}$ & $4.25 \times 10^{-3}$ & $6.28 \times 10^{-1}$ \\
C11 & $2.50 \times 10^{-3}$ & $4.76 \times 10^{-3}$ & $5.25 \times 10^{-1}$ \\
\hline
\end{tabular}

$A P P$, amyloid precursor protein.

of every section at a magnification of $\mathrm{x} 200$. The proportions of positive cells were stratified into four groups: $1,<10 \%$; 2, 11-29\%; 3, 30-50\%; and 4, >50\%. A statistical analysis was performed with the Cochran-Mantel-Haenszel test $(\mathrm{P}<0.05$ used to indicate a statistically significant difference). For immunofluorescence, a fluorescence intensity analysis was performed using one-way analysis of variance analysis, followed by the t-test. $\mathrm{P}<0.05$ was considered to indicate a statistically significant difference.

\section{Results}

Total RNA was successfully isolated from brain tissues of individual samples selected randomly from the two groups. $\mathrm{A}_{260}, \mathrm{~A}_{280}$ and $\mathrm{A}_{260} / \mathrm{A}_{280}$ values are listed in Table III.

No differences were identified between the epileptic and control groups with regard to the APP mRNA concentrations in the temporal lobe and hippocampal tissue samples. The target amounts of mRNA amplified from the epileptic temporal lobe and hippocampal tissue samples arrived at a $\mathrm{Ct}$ value almost at the same time as the following 40 amplified reaction cycles. Table IV presents the normalized target values obtained by dividing the target amount by the $\beta$-actin values. There was no significant difference between the epileptic tissue and control samples.

Histopathological staining. Almost all the tissue samples from the epileptic group demonstrated damage. Cortical laminar 
Table V. $\beta$-APP immunocytochemical expression in the two groups.

\begin{tabular}{lccr}
\hline Tissue samples & $\begin{array}{c}\text { Experimental group } \\
\text { ratio of positive cells, \% (n) }\end{array}$ & $\begin{array}{c}\text { Control group } \\
\text { ratio of positive cells, \% (n) }\end{array}$ & P-value \\
\hline Temporal lobe & $70.59(36)$ & $29.41(15)$ & 0.0001 \\
Hippocampus & $58.33(7)$ & $41.67(5)$ & 0.0009 \\
\hline
\end{tabular}

$A P P$, amyloid precursor protein.

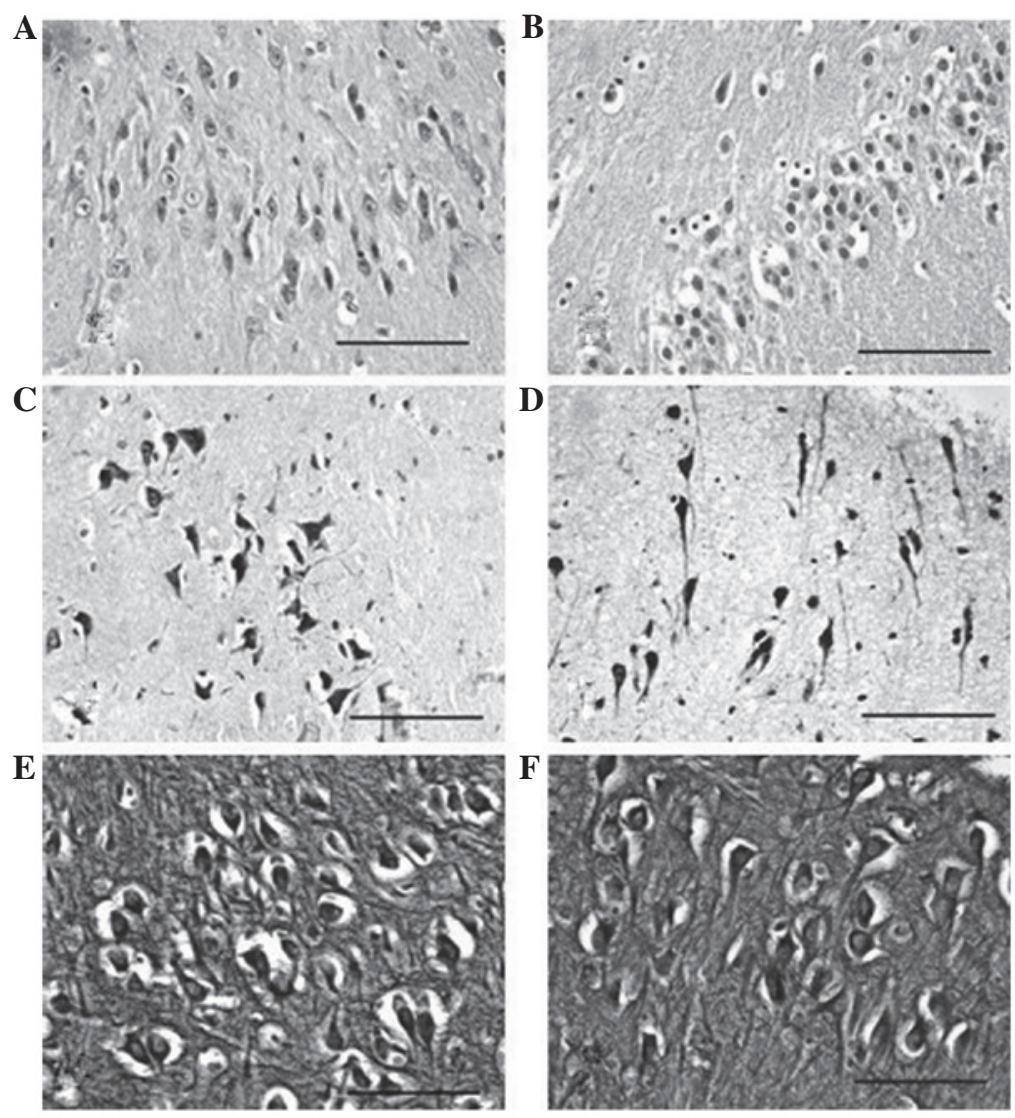

Figure 1. Pathological staining. HE and Nissl staining indicating lost neurons, degeneration and axon derangement in temporal lobe and hippocampal tissue samples of patients with refractory epilepsy compared with the control group. Silver nitrate staining revealed neuron and axon derangement in hippocampal tissue samples of patients with RTLE. (A) HE stain, hippocampus of patient with RTLE; (B) HE stain, hippocampus of the control; (C) Nissl stain, temporal lobe tissue of patient with RTLE; (D) Nissl stain, temporal lobe tissue of the control; (E) silver nitrate stain, hippocampus pyramidal cells of patient with RTLE; and (F) silver nitrate stain, hippocampus pyramidal cells of the control. Scale bars, $100 \mu \mathrm{m}$. HE, hematoxylin-eosin. RTLE, refractory epilepsy.

disorganization, neuronal loss, balloon cell change, gliosis, associated cytoskeletal abnormalities and abnormal axon organization were observed in the temporal lobe samples. The granular cell layer of the hippocampus exhibited dispersion of the neuronal cells and axonal disarray. Fig. 1 shows examples of histopathological staining.

Immunoreactivity. In total, 36 epileptic and 15 control tissue samples were subjected to immunohistochemical staining. In the temporal cortex and hippocampus tissue samples of patients with epilepsy, markedly positive staining for $\beta-A P P$ protein was observed, whereas the distribution of $\beta-A P P$ positive protein staining was quite faint in the control sections. No positive staining for protein was identified in the matrix.
$\beta-A P P$ staining was also evident in hippocampal tissue from the 68-year-old male with AD who was used as a positive control. No immunoreactivity was observed in the negative controls (temporal cortex tissue samples with no primary antibody). Fig. 2 shows the result of DAB staining. The average proportion of $\beta-A P P$-stained cells in the temporal lobe and hippocampus in the experimental group was significantly greater compared with that of the control group $(\mathrm{P}<0.05)$. Table $\mathrm{V}$ lists values of the $\beta-A P P$ immunocytochemical expression in the experimental and control groups.

Immunofluorescence. Markedly positive staining for $\beta$-APP protein was observed in the temporal cortex and hippocampal tissue of the patients with epilepsy, as demonstrated by green 
Table VI. Immunofluorescence intensity of $\beta-A P P$ in the two groups.

\begin{tabular}{|c|c|c|c|c|}
\hline Tissue samples & $\begin{array}{c}\text { Experimental group, } \\
\text { mean } \pm \mathrm{SD}\end{array}$ & $\begin{array}{l}\text { Control group, } \\
\text { mean } \pm \mathrm{SD}\end{array}$ & $\mathrm{t}$ or $\mathrm{t}^{\prime}$ value & $\mathrm{P}$-value \\
\hline Temporal lobe & $29.25 \pm 1.71$ & $9.74 \pm 1.36$ & 36.92 & $<.0001$ \\
\hline Hippocampus & $32.79 \pm 2.68$ & $13.87 \pm 1.66$ & 17 & $<.0001$ \\
\hline
\end{tabular}

$A P P$, amyloid precursor protein; $\mathrm{SD}$, standard deviation.
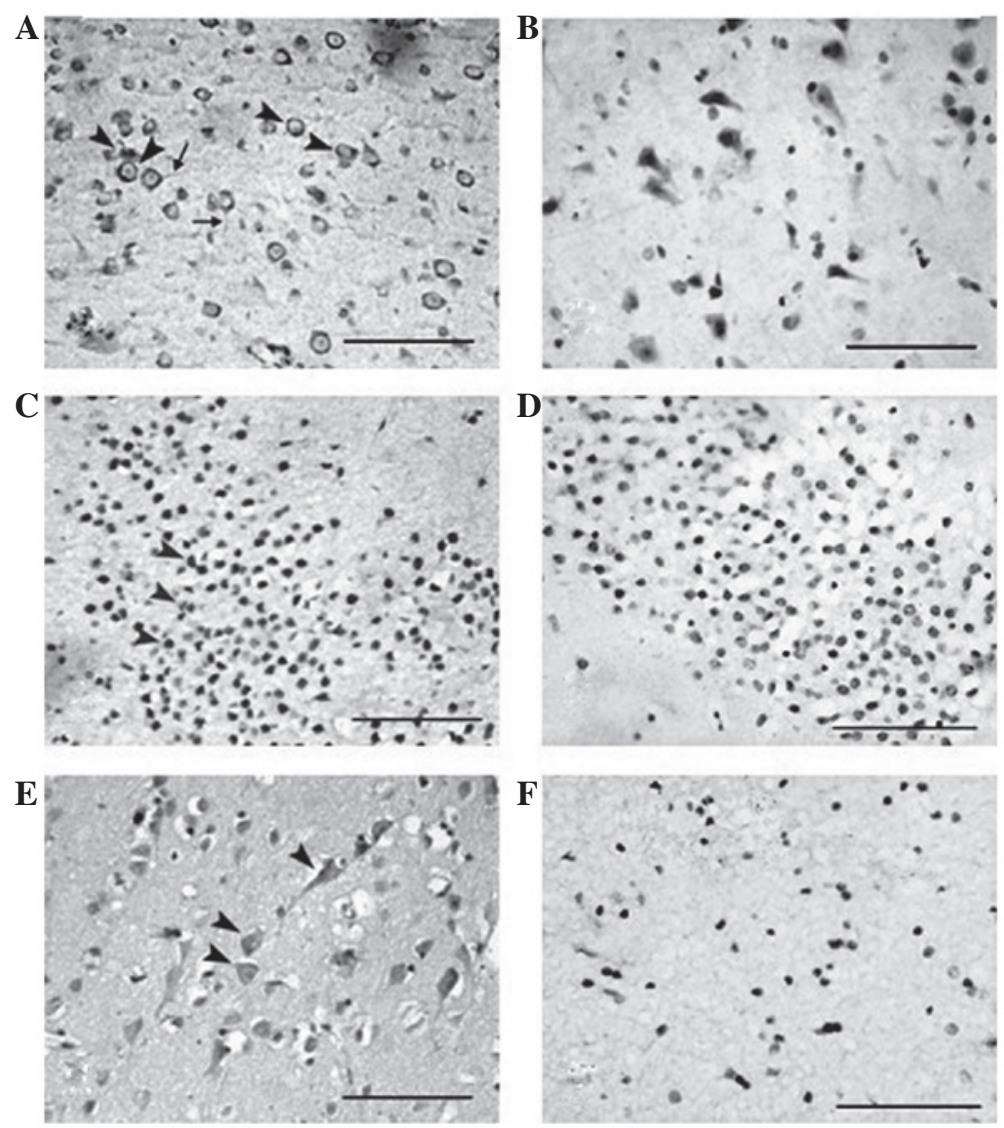

Figure 2. Immunohistochemistry results. Cells stained markedly positive for $\beta-A P P$ in intractable epilepsy. (A) Neuronal cells stained for $\beta$ - $A P P$ in epileptic temporal lobe tissue. The broad arrow indicates positively-stained cells and the thin arrow indicates positively-stained axons. No positive protein staining was observed in the matrix. (B) Temporal lobe of the control. (C) Positively-stained dentate cells in epileptic hippocampi. (D) Dentate cells in the control. (E) Positively-stained control from a 68-year-old male with AD. (F) Negative control. Scale bars, $100 \mu \mathrm{m}$. APP, amyloid precursor protein; AD, Alzheimer's disease.

fluorescent light and immunofluorescence staining, whereas the distribution of $\beta-A P P$-positive protein staining in the control sections was relatively faint. Fig. 3 demonstrates the results of the immunofluorescence staining. The expression of $\beta-A P P$ was significantly greater in the epileptic tissue compared with the control samples $(\mathrm{P}<0.05)$. Table VI shows the statistical results of $\beta-A P P$ fluorescence intensity in the experimental and control groups.

\section{Discussion}

In the present study, no changes in $A P P$ mRNA expression levels were identified, but the levels of $\beta-A P P$ expression in the experimental group were greater compared with those of the control group. This result indicates that high expression levels of $\beta-A P P$ protein are not associated with $A P P$ mRNA levels. In the temporal lobe and hippocampal tissue samples from patients with refractory epilepsy, $\beta-A P P$ protein accumulated in the neuronal cytoplasm and axons, as revealed by immunostaining. No extracellular fibrillar accumulation of $\beta-A P P$ as senile plaques was identified. It appeared that the decomposition process of $\beta-A P P$ has a role in AD. These results indicate that high expression levels of $\beta-A P P$ have a key role in the pathological mechanisms underlying refractory epilepsy, but not in the same manner by which this protein leads to AD.

In studies on the development of chronic epilepsy, a number of changes in the pathology of the neural network have been revealed. Radhakrishnan et al (8) identified that axonal fibers 

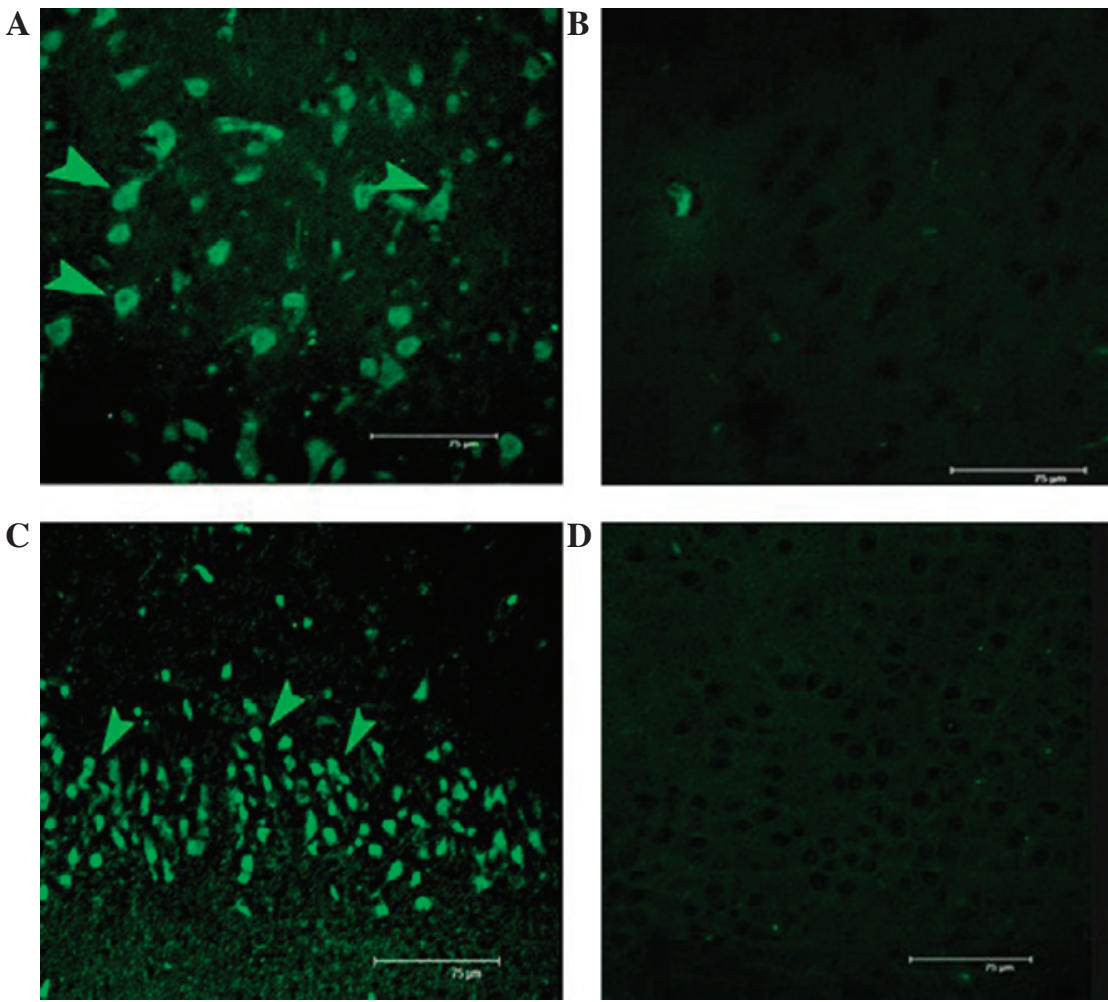

Figure 3. Immunofluorescence results. $\beta-A P P$ fluorescence stain accumulated in the cytoplasm and axons of the neuronal cells. (A) $\beta$ - $A P P$-positive staining for cells in temporal lobe tissue samples of patients with intractable epilepsy. (B) Faint fluorescence expressed in temporal lobe tissue of the control. (C) Positive staining in the granular cell layer in epileptic hippocampus tissue. (D) The hippocampus granular cell layer in the control. The green arrows point to the positively-stained cells. Scale bars, $75 \mu \mathrm{m}$. $A P P$, amyloid precursor protein.

between the neurons were absent. In the present study, axonal fiber disarray was also evident in histopathological staining. Axonal sprouting and synaptic reorganization following neuronal injury also have a key role in the pathogenesis of refractory epilepsy (9). The network structure is assumed to cause epileptiform activity in refractory epilepsy and create or strengthen recurrent excitation in other brain regions (10). However, the concrete molecular mechanism of axonal damage and neuronal circuit reorganization remains to be elucidated.

$\beta-A P P$, derived from $A P P$, is a type of membrane protein present on the surface of neuronal and glial cells (11). In addition to its classic role as a toxin to neurons, it is apparent that $\beta-A P P$ has a role in the pathogenesis of axon damage. Intracellular $\beta-A P P$ accumulation is the major finding in the senile plaques and neurofibrae tangle that may cause perturbed axonal transport in AD (12). In a number of cases, immunostaining for $\beta-A P P$ is used to detect axonal injury $(13,14)$. As mentioned previously, axonal damage is also the distinguishing characteristic of refractory epilepsy. It is therefore indicated that the overexpression of $\beta-A P P$ in refractory epilepsy is involved in the process of neuronal network damage.

$\beta-A P P$, which modulates axonogenesis and neuronal polarity, is necessary for normal axon growth. In the axons of growing cones of embryonic neurons, APP is expressed at high levels for neurite development (6). In one study, cultured hippocampal neurons from $\beta$ - $A P P$-deficient mice revealed dysfunctional axon growth compared with wild type mice (15). The increased expression of $\beta-A P P$ is accompanied by an unusual accumulation of neurofilaments following stereotaxic microinjection of $N$-methyl-D-aspartate or $\alpha$-amino-3-hydrox y-5-methylisoxazole-4-propionic acid to the rat hippocampal CA1 area (16). Other studies also support the finding that the overexpression of $\beta-A P P$ modulates axonogenesis and neuronal polarity in pathological conditions (17).

$\beta-A P P$ may have a function in axon growth by promoting phosphorylation of the tau protein $(\tau)$. The increased phosphorylation of $\tau$ was also identified in a rat model of temporal lobe epilepsy, and increased $\tau$ phosphorylation was associated with the appearance of mossy sprouting (18). $\beta$-APP induces and facilitates the development of $\tau$ pathology $(19,20)$ and induces $\tau$ phosphorylation through direct or indirect activation of glycogen synthase kinase 3 , mitogen-activated protein kinase, apoptosis signal-regulating kinase 1, protein kinase MKK6 and P38 mitogen-activated protein kinase (21-23). These pathways may have a role in abnormal neutrite growth.

Although it is clear that $\beta-A P P$ has a role in the pathogenesis of chronic epilepsy, the mechanism behind abnormally increased $\beta-A P P$ remains to be elucidated. Kalaria et al (24) indicated that $A P P$ is induced by ischemic insults or chronic hypoperfusion. In refractory epilepsy, repeated seizures are often accompanied with focal ischemic insults, and hypoperfusion may be a factor of the overexpression of $\beta-A P P$. Further studies are required in order to investigate the role that the increased expression of $\beta-A P P$ may have in neural network damage and reorganization.

\section{Acknowledgements}

This study was supported by the National Natural Science Foundation (nos 30872646 and 30973082). 


\section{References}

1. Lozsadi DA and Larner AJ: Prevalence and causes of seizures at the time of diagnosis of probable Alzheimer's disease. Dement Geriatr Cogn Disord 22: 121-124, 2006.

2. Del Vecchio RA, Gold LH, Novick SJ, Wong G and Hyde LA: Increased seizure threshold and severity in young transgenic CRND8 mice. Neurosci Lett 367: 164-167, 2004.

3. Shoham S and Ebstein RP: The distribution of beta-amyloid precursor protein in rat cortex after systemic kainate-induced seizures. Exp Neurol 147: 361-376, 1997.

4. Sheng JG, Boop FA, Mrak RE and Griffin WS: Increased neuronal beta-amyloid precursor protein expression in human temporal lobe epilepsy: association with interleukin-1 alpha immunoreactivity. J Neurochem 63: 1872-1879, 1994.

5. Willoughby DA, Johnson SA, Pasinetti GM, et al: Amyloid precursor protein mRNA encoding the Kunitz protease inhibitor domain is increased by kainic acid-induced seizures in rat hippocampus. Exp Neurol 118: 332-339, 1992.

6. Ferreira A, Caceres A and Kosik KS: Intraneuronal compartments of the amyloid precursor protein. J Neurosci 13: 3112-3123, 1993.

7. Wieser HG, Blume WT, Fish D, et al: ILAE Commission Report. Proposal for a new classification of outcome with respect to epileptic seizures following epilepsy surgery. Epilepsia 42: 282-286, 2001

8. Radhakrishnan VV, Rao MB, Radhakrishnan K, et al: Pathology of temporal lobe epilepsy: An analysis of 100 consecutive surgical specimens from patients with medically refractory epilepsy. Neurol India 47: 196-201, 1999.

9. Larner AJ: Axonal sprouting and synaptogenesis in temporal lobe epilepsy: possible pathogenetic and therapeutic roles of neurite growth inhibitory factors. Seizure 4: 249-258, 1995.

10. Nadler JV: The recurrent mossy fiber pathway of the epileptic brain. Neurochem Res 28: 1649-1658, 2003.

11. Yamazaki T, Selkoe DJ and Koo EH: Trafficking of cell surface beta-amyloid precursor protein: retrograde and transcytotic transport in cultured neurons. J Cell Biol 129: 431-442, 1995.

12. Kins S, Lauther N, Szodorai A and Beyreuther K: Subcellular trafficking of the amyloid precursor protein gene family and its pathogenic role in Alzheimer's disease. Neurodegener Dis 3: 218-226, 2006

13. Smith DH, Uryu K, Saatman KE, Trojanowski JQ and McIntosh TK: Protein accumulation in traumatic brain injury. Neuromolecular Med 4: 59-72, 2003.
14. Bramlett HM, Kraydieh S, Green EJ and Dietrich WD: Temporal and regional patterns of axonal damage following traumatic brain injury: a beta-amyloid precursor protein immunocytochemical study in rats. J Neuropathol Exp Neurol 56: 1132-1141, 1997.

15. Perez RG, Zheng H, Van der Ploeg LH and Koo EH: The beta-amyloid precursor protein of Alzheimer's disease enhances neuron viability and modulates neuronal polarity. J Neurosci 17: 9407-9414, 1997.

16. Gordon-Krajcer W and Gajkowska B: Excitotoxicity-induced expression of amyloid precursor protein (beta- $A P P$ ) in the hippocampus and cortex of rat brain. An electron-microscopy and biochemical study. Folia Neuropathol 39: 163-173, 2001.

17. Zhu JL, Zhu SH and Ren L: Expression of beta-amyloid precursor protein in diffuse axonal injury of rats. Fa Yi Xue Za Zhi 21: 165-168, 2005 (In Chinese).

18. Pollard H,Khrestchatisky M, Moreau J,Ben-Ari Y and Represa A: Correlation between reactive sprouting and microtubule protein expression in epileptic hippocampus. Neuroscience 61: 773-787, 1994.

19. Blurton-Jones M and Laferla FM: Pathways by which Abeta facilitates tau pathology. Curr Alzheimer Res 3: 437-448, 2006.

20. Pavia J, de Ceballos ML and Sanchez de la Cuesta F: Alzheimer's disease: relationship between muscarinic cholinergic receptors, beta-amyloid and tau proteins. Fundam Clin Pharmacol 12: 473-481, 1998.

21. Wang ZF, Li HL, Li XC, et al: Effects of endogenous beta-amyloid overproduction on tau phosphorylation in cell culture. J Neurochem 98: 1167-1175, 2006.

22. Ghribi O, Larsen B, Schrag M and Herman MM: High cholesterol content in neurons increases BACE, beta-amyloid, and phosphorylated tau levels in rabbit hippocampus. Exp Neurol 200: 460-467, 2006

23. Peel AL, Sorscher N, Kim JY, Galvan V, Chen S and Bredesen DE: Tau phosphorylation in Alzheimer's disease: potential involvement of an APP-MAP kinase complex. Neuromolecular Med 5: 205-218, 2004.

24. Kalaria RN, Bhatti SU, Lust WD and Perry G: The amyloid precursor protein in ischemic brain injury and chronic hypoperfusion. Ann NY Acad Sci 695: 190-193, 1993. 